\title{
Are Emotions Important for College Teachers' Intentions to Use the Online Learning System? An Integrated Model of TAM and PAD
}

\author{
Yiming Qu and I-Hua Chen
}

\begin{abstract}
Project based learning(PBL) is an innovative instructional strategy focusing on practice and participation, which emphasizes problem solving and integrates a variety of authentic learning approaches. As such, PBL is an appropriate instructional strategy to realize "learner-centered" and "ability-centered" education. As the core of teaching, whether teachers are willing to use the online system for PBL has become a key factor. Based on this, to investigate the influence of teachers' emotions on their intention to use the PBL online system is helpful to improve teachers' teaching. Using 196 Taiwan college teachers attending the workshops of PBL online system as the participants, this study combined TAM (Technology Acceptance Model) with PAD (pleasure, arousal, dominance) to propose a new, integrated model to clarify the impact of teachers' emotions on the intentions to use the PBL online system. The results showed that: Among the original TAM, the variables of perceived usefulness and perceived ease of use were positive to the attitude and the attitude was positive to the intention of using the PBL online system; For the variables of PAD, the variables of pleasure and arousal were positive to the attitude and the variable of dominance was positive to the variable of perceived ease of use.
\end{abstract}

Index Terms -Emotion, project based learning online system, technology acceptance model.

\section{RESEARCH BACKGROUND AND PURPOSE}

Project based learning(PBL) is a very popular and innovative teaching method in recent years. It means that teachers encourage students to actively solve a problem related to real life experience. To solve this problem, students need to define and analyze the essence of it and systematically collect all kinds of information to conceive a strategy for solving the problem, and finally implement this solution to evaluate the effectiveness of it. PBL not only allows students to acquire the knowledge related to the curriculum, but also cultivates their problem-solving skills, self-management skills and communication and cooperation skills [1], [2], so they are highly valued by educators. In the trend of promoting PBL, many studies have shown that this method is quite suitable for practice with distance education [3], [4], because PBL emphasizes students' ability of

Manuscript received June 19, 2020; revised November 1, 2020.

Yiming Qu is with the Department of Educational Management, Krirk University, Bangkok, Thailand. $\mathrm{He}$ is also with Zhengzhou Shengda University of Economics and Trade Management College, China (e-mail: yimingqym@163.com).

I-Hua Chen is with Chinese Academy of Education Big Data, Qufu Normal University, Shandong, China (e-mail: aholechen@gmail.com). self-planning learning which is consistent with the "student-centered" spirit of online education. Moreover, under the Internet environment, distance education can offer rich information for students' information exploration activities required by PBL. In other words, the combination of PBL and online education is complementary.

If PBL is to be implemented under the distance education environment, the most important thing is to digitize course materials. To facilitate teachers to carry out this work easily, some online systems have recently appeared, which can assist teachers in completing PBL efficiently in a step-by-step manner. For instance, those systems include ProjectFoundry (http://www.projectfoundry.org) abroad and Qunxue (http://cop.linc.hinet.net/) and Zhizhi (http://twpbl.org/) in Taiwan . Taking Zhizhi as an example, the system divides the course modules of PBL into four main blocks: situation arrangement, task setting, network resources and learning evaluation. Under the structure, teachers can focus on the situation and task setting of PBL and do not need to worry about the layout of teaching materials, which effectively shortens the time of designing PBL course. Since the network teaching system such as Zhizhi can improve the efficiency of PBL course and also achieve the benefit of sharing teaching resources, with the course modules spreading through the Internet, so it is expected that there will be more online systems in the future. However, to make teachers use these systems actively requires a comprehensive training plan. The key is to allow teachers to generate the willingness to use this system for PBL in the training process. From this point of view, what factors involved in the activity will affect their subsequent intentions to use the system is the first problem to be clarified, which will provide more grounds to follow in the future's training plan.

In the past few years, many studies based on the technology acceptance model (TAM) proposed by Davis [5] have been used to explore the intention of college teachers to use online teaching or information technology [6]-[10]. It has accumulated quite fruitful results, and also initially confirmed the basic elements of TAM--perceived usefulness and perceived ease of use can effectively explain teachers intention to use these information technologies for teaching. It is a pity that although these studies have included the external task environment, teachers' characteristics, teachers' subjective perception and other factors into the model for testing, they still ignore the emotions of teachers when using the network or information technology which may also affect its usage intention. In fact, emotions are the most direct instincts of people, and they are often directly reflected in the external behavior of individuals. In recent years, some 
scholars have begun to notice the impact of emotions on the technology usage for individuals [11]-[13]. However, research on this topic is still a minority, and there is still much room for further development.

Taking the above into consideration, it is an important problem to find out what kind of factors will affect teachers' intentions to use the system during the training activities of project based learning online system. However, those TAM studies about teachers' technology usage intentions do not consider the effects of emotions. As such, for teachers participating in training activities, this study combines TAM and emotional factors to construct a new integrated model in the form of structural equation modeling to discuss the influence of basic variables of TAM and emotional variables on the teachers' usage intention in project based learning online system.

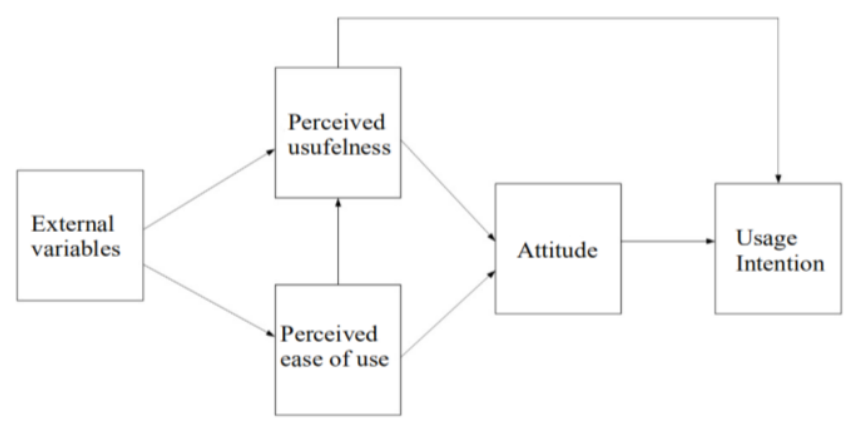

Fig. 1. Original TAM architecture.

\section{LITERATURE DISCUSSION}

\section{A. TAM}

The TAM proposed by Davis is based on the perspectives of social cognitive and behavioral decision. It is believed that the intention of individuals to use a specific technology will be affected by their attitudes towards this technology, and the development of attitudes depends on the individual's judgement of the perceived usefulness and perceived ease of use of the technology. The basic theoretical framework is shown in the below. In short, TAM believes that individual attitudes, perceived usefulness, and perceived ease of use can be used to explain the intention to use technology, and this theory has been supported by many empirical studies [6]-[9] [14], [15].

After Davis proposed TAM, the model has gained the attention of many scholars. When a new explanatory variable is incorporated into the original model, it is called the modified TAM. For example, Si Zhang and Yongfan Li [9] subdivided the external variables of the original TAM into social routines, individual characteristics (self-efficacy) and system characteristics (system practicality), and constructed another integrated model; Lina Yang and Zhijun Yan [10] not only tested the impact of original TAM variables on behavioral intentions but also discussed new variables such as individual identification of the environment and the quality of information provided by the system. It is undeniable that compared with the original TAM, the modified TAM has a considerable improvement in the explanatory power of individual behavior intentions due to the addition of new explanatory variables. Nonetheless, the complexity of the model is also increased, which is the price to add multiple explanatory variables. The main point of this study is to examine the effect of the original TAM on teachers' intentions in training activities, and also to test the effect of emotional variables. In this case, if a complex modification is used, there will be problems caused by too many model constructs. So according to the parsimoniously, it is more appropriate for the study to adopt the original TAM architecture.

\section{B. Emotion}

According to the Zhang's Dictionary of Psychology, emotion is an individual's conscious psychological imbalance caused by a certain stimulus. Individuals' emotional feelings are easy to be directly reflected in their explicit behavior, and this is also reflected in the impact on the use of individual technology. For example, in the study of Kay[12], the emotions felt by pre-service teachers when learning new information technology will become the reference standard for whether they should adopt the technology in the future; Anderson and others [11] surveyed more than 1,000 high school female students and later found that the feelings (interesting and boring) of computers will affect whether those students will continue to choose advanced computer courses; Sanchez-Franco's [13] research also shows that college students' emotions in the network environment will influence the effectiveness of their online learning.

There are quite a few types of human emotions. If one wants to include multiple emotions into the integrated model for testing at the same time, he must use a systematic approach. Otherwise, some emotions that are different names but with similar emotional responses will be incorporate into the explanatory model together to cause the adverse effects of mutual interference. At this time, the PAD(pleasure, arousal, dominance) emotion model of Mehrabian [16] provides an appropriate classification framework. PAD divides human emotions into three dimensions: pleasure, arousal, and dominance, and believes that any emotion can find a corresponding position in this three-dimensional space. In view of the fact that PAD can systematically cover human emotions, this study combined the three variables of PAD with the original TAM.

\section{Research Hypothesis}

The integrated model in this research integrated the three variables of the original TAM: perceived usefulness, perceived ease of use and attitude, into the three variables of PAD: pleasure, arousal and dominance simultaneously for testing to explain the technology usage intention of teachers in training activities. Because previous studies have shown that emotion directly affects the individual attitude [17], and when the attitude is affected, it indirectly changes the judgment on the usage intention. Therefore, in the integrated model of this study, the three PAD emotional variables were set to directly affect attitude. In addition, among the three emotions of PAD, dominance is inextricably linked to perceived ease of use, except for the direct influence on attitude caused by it. Because logically, when an individual has dominance on a particular technology, the one is likely to 
think that the technology will be easy to use. The following is an explanation of the relevant assumptions.

1) The relationship between the attitude and the usage intention: Hypothesis $\mathrm{H}_{1 \mathrm{a}}$

In the original TAM, individual attitudes were assumed to directly affect their technology usage intention. However, attitude variables are not included in the model test in many TAM studies [13], [15], [18]. The main reason is that these studies have found that when TAM is used to explain an employee's intention to use technology, because employees tend to view technology use as a tool for improving work efficiency or promotion, even if the attitude toward the technology is negative, there may still be a high usage intention. In other words, in enterprises, the relationship between attitude variables and technology usage intentions does not necessarily exist. Nonetheless, Athiyaman [19] pointed out that attitudes may still have a significant influence on an individual's intention to use technology, but the applied situation is where to give individuals more opportunities for free selection. Since the object of this study is teachers, in general, teachers can decide by themselves whether they want to use the technology acquired in training activities. Therefore, in this study, it is still assumed that the attitude is positive to the usage intention.

2) The relationship between perceived usefulness, perceived ease of use, the attitude and the usage intention: Hypotheses $\mathrm{H}_{1 \mathrm{~b}}, \mathrm{H}_{1 \mathrm{c}}, \mathrm{H}_{1 \mathrm{~d}}$

Perceived usefulness and perceived ease of use are the most frequently discussed variables that affect an individual's attitude toward technology use. Previous empirical studies have shown that individuals' perceived usefulness and perceived ease of use of technology have a direct and positive effect on the attitude [14], [20], while perceived usefulness will directly promote individuals' intentions of technology usage [15], [21]. Accordingly, the hypotheses proposed by this study is: perceived usefulness is positive to the attitude $\left(\mathrm{H}_{1 \mathrm{c}}\right)$; perceived ease of use is positive to the attitude $\left(\mathrm{H}_{1 \mathrm{~d}}\right)$; perceived usefulness is positive to the usage intention $\left(\mathrm{H}_{1 \mathrm{~b}}\right)$.

3) The relationship between pleasure and the attitude: $\mathrm{H}_{2 a}$

Among the PAD, pleasure is composed of arrays of opposite emotional adjectives, such as happy-unhappy and happy-annoying [16]. Bruner and Kumar [22] found that pleasure will directly affect users' attitudes towards using handheld devices; Kay [12] pointed out that pleasure is the key factor for pre-service teachers to continue to use computers in the classroom. Based on the above, this study assumed that pleasure is positive to the attitude.

4) The relationship between arousal and the attitude: Hypothesis $\mathrm{H}_{2 \mathrm{~b}}$

The arousal refers to an emotional state in which the individual's body and mind are in alertness. Among the PAD, arousal also includes multiple opposite emotional adjectives, including excitement-calmness, stimulation-relaxation, etc. O'Regan's [23] research found that the college students' arousal and stimulus brought by the technology when browsing the Internet will affect whether they will continue to $\log$ on to the website. Based on this, the researchers assumed that arousal are positive to the attitude.
5) The relationship between dominance and the attitude: Hypothesis $\mathrm{H}_{2 \mathrm{c}}$

The dominance refers to the emotional response that the individual feels to be able to control the environment in which he is or the task that he is engaged in. Among the PAD, dominance contains a series of opposite emotional adjectives, such as controllable-controlled. In past empirical studies on dominance and technology usage, anxiety was the most commonly discussed type of dominance [12]. Because the individual feels to be unable to control the technology used, anxiety will be produced, and this negative emotion tends to cause the individual to hold a negative attitude towards this technology. However, there is another possibility that when users have a high degree of dominance about technology, it will generate boredom and then negative attitudes. Since there is not many researches available for reference at present, the researchers assumed that the dominance is related to the attitude, but do not assume its directionality.

6) The relationship between dominance and perceived ease of use: Hypothesis $\mathrm{H}_{2 \mathrm{~d}}$

In terms of the essence of dominance, it may directly affect the individual's perceived ease of use of the technology. As mentioned before, perceived ease of use is the degree of ease of use that an individual perceives when using a particular technology, while dominance is the emotion that dominates the technology used. Based on this, in terms of logical experience, the higher the individual's dominance of a particular technology, the higher the degree of perceived ease of use of the technology, and the two should be positive.

7) Adjustment effect of gender variable: Hypothesis $\mathrm{H}_{3}$

The difference of technology usage between the genders has always been a topic of great concern. Past researches showed that even in a modern society where technology has been gradually popularized, men still have more experience in technology usage than women [11], [24]. And this difference is likely to result in different degrees of perceived ease of use to a particular technology between the sexes. Among the TAM, perceived ease of use is assumed to directly affect an individual's attitude toward technology usage. Due to the difference in the experience of using technology between men and women, their judgments of perceived ease of use also differ, which may further lead to a situation that the influence of perceived ease of use on attitudes must be determined by gender, that is, gender variables may have an adjustment effect on the relationship between perceived ease of use and the attitude. Venkatesh and Morris [18] found that gender has an regulative effect on the influence of perceived ease of use to usage intention, but the study did not incorporate attitude variables, so it is not possible to directly infer whether gender can regulate the effect of perceived ease of use on attitude. This part needs to be tested in this study.

\section{RESEARCH METHOD}

\section{A. Research Object}

In this study, six workshop training activities on project based learning online system were held in the northern, central, southern, and eastern regions of Taiwan, and teachers 
attending these six workshops were used as test samples to verify the model. The main function of the online system in the workshops is to assist teachers in efficiently implementing PBL courses, and the main purpose of workshops is to help those teachers familiarize with the operation of the system. In order to avoid possible external factors, these six workshops hired the same speakers and had the same content. A total of 235 teachers participated in the workshop. After excluding the number of incomplete answers and refusals, there were 196 valid samples, with an average age of 35.4 years $(\mathrm{SD}=6.72), 57$ males, and 139 females, all from institutions of higher education in Taiwan.

\section{B. Data Measurement}

The measurement of the variable of usage intention used in this study was completed to obtain the respondent data by email after the workshop. But apart form that, the rest including the information skills of the subjects and the original TAM variables (perceived usefulness, perceived ease of use, attitude) and PAD variables (pleasure, arousal and dominance) were all measured in paper form immediately after the workshop. The measurement tools used in this model, except that the two items of attitude were compiled by the researchers themselves, the remaining measurement items were all based on the scales used in past empirical studies, with minor modifications to make the content of the items more suitable for the context of this study. The content of each item is shown in Table I. The research tools shown in Table I all adopted the scoring form of Likert scale, except that the PAD scale adopted a nine-point scale, and the rest were scored at six point.

TABLE I: RESEARCH TOOL

\begin{tabular}{|c|c|c|}
\hline $\begin{array}{l}\text { Latent } \\
\text { variable }\end{array}$ & Item & Source \\
\hline \multirow[t]{3}{*}{ Perceived usefulness } & $\begin{array}{l}\text { I think that using the online system in the workshop can improve the efficiency of implementing PBL } \\
\text { courses. }\end{array}$ & \multirow[t]{3}{*}{ Park [20] } \\
\hline & Using the online system in the workshop allows me to complete PBL course quickly. & \\
\hline & Using PBL courses of the online system in the workshop can effectively help students' learning. & \\
\hline \multirow{6}{*}{$\begin{array}{l}\text { Perceived } \\
\text { ease of use }\end{array}$} & It is easy for me to learn how to operate the online system in the workshop. & \multirow[t]{6}{*}{ Davis [5] } \\
\hline & I can operate the online system in the workshop as I want. & \\
\hline & I think the online system in the workshop gave me clear interactive operation experience. & \\
\hline & I think the online system in the workshop has flexible but not rigid operation. & \\
\hline & For me, it is easy to master the online system in the workshop. & \\
\hline & I think the online system in the workshop is easy to operate. & \\
\hline \multirow[t]{2}{*}{ Attitude } & I think the online system in the workshop is important. & \multirow{2}{*}{$\begin{array}{l}\text { Researcher } \\
\text { complied }\end{array}$} \\
\hline & I think the online system in the workshop has positive significance for my teaching. & \\
\hline \multirow[t]{6}{*}{ Usage intention } & When implementing PBL, I will want to use the online system in the workshop. & \multirow[t]{6}{*}[14]{} \\
\hline & When I need it, I will want to use the online system in the workshop. & \\
\hline & I will continue to use the online system in the workshop. & \\
\hline & I will use every function of the online system in the workshop as much as possible. & \\
\hline & Whenever I need to implement a PBL course, I will want to use the online system in the workshop. & \\
\hline & I will often use the online system in the workshop. & \\
\hline \multirow[t]{6}{*}{ Pleasure } & 1. Happy/unhappy & \multirow[t]{18}{*}{ [16] } \\
\hline & 2. Happy/annoying & \\
\hline & 3. Satisfied/dissatisfied & \\
\hline & 4. Contented/sorrowful & \\
\hline & 5. Hopeful/desperate & \\
\hline & 6. Leisurely/boring & \\
\hline \multirow[t]{6}{*}{ Arousal } & 1. Stimulating/relaxing & \\
\hline & 2. Excited/cool & \\
\hline & 3. Inspiring/lazy & \\
\hline & 4. Nervous / dull & \\
\hline & 5. Mental/sleepy & \\
\hline & 6. Excited/calm & \\
\hline \multirow[t]{6}{*}{ Dominance } & 1. Controllable/protected & \\
\hline & 2. Dominant / dominated & \\
\hline & 3. Leading/submissive & \\
\hline & 4. Influential/influenced & \\
\hline & 5. Independent/affected & \\
\hline & 6. Confident/afraid & \\
\hline
\end{tabular}

In addition to the measurement tools listed in Table I that are directly related to the variables discussed in this study, because the subjects are college teachers from different regions of Taiwan, in order to avoid the different regions to cause different information skills which will interfere with this model, the researchers compiled an information skill questionnaire to evaluate the information skills of the subjects. After analysis, the overall Cronbach's $\alpha$ of the questionnaire was 0.82 .

\section{Research Model and Hypothesis}

After discussing the literature, the researchers put forward the research model in Fig. 2. In terms of latent variables, this model includes four latent independent variables (perceived usefulness, pleasure, arousal and dominance) and three latent dependent variables (perceived ease of use, attitude and usage intention). In the measured variable, the researchers packaged the measurement items with item parceling, so that each latent variable corresponds to two packaged measured variables, so there are 14 derivative measured variables. This model has a total of 14 measured variables, which will generate 105 measurement data $(\mathrm{DP}=1 / 2 * 14 * 15)$, with 42 estimated parameters required by the model, so $t<105$ over 
identification meets Bollen's $t$-Rule verification standard.

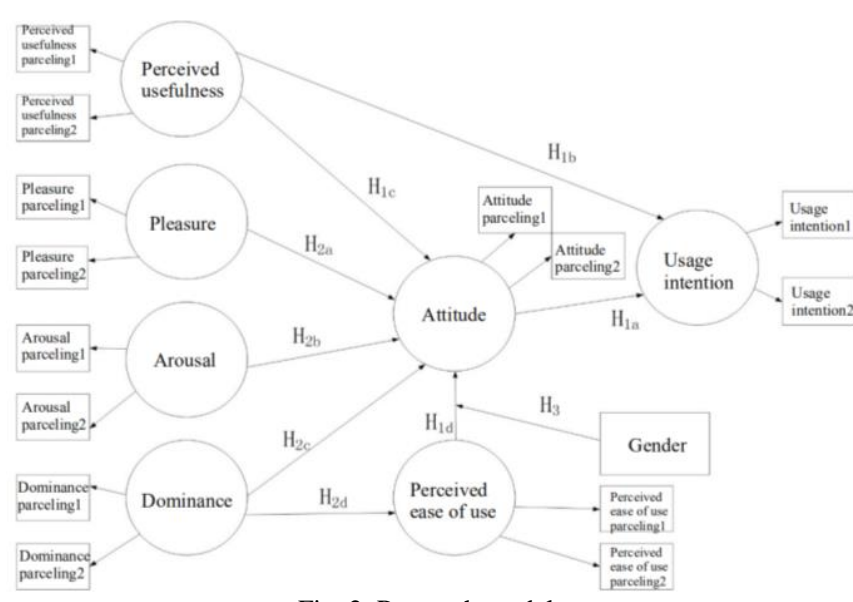

Fig. 2. Research model.

This study first confirmed the overall fit between the model and the empirical data, and secondly tested the significance of each coefficient (research hypothesis). The hypotheses are shown in Table II.

TABLE II: RESEARCH HYPOTHESES

\begin{tabular}{|c|c|}
\hline $\begin{array}{l}\text { Research } \\
\text { hypothesis }\end{array}$ & Content \\
\hline $\mathrm{H}_{1 \mathrm{a}}$ & The attitude is positive to the usage intention. \\
\hline $\mathrm{H}_{1 \mathrm{~b}}$ & $\begin{array}{l}\text { The perceived usefulness is positive to the usage } \\
\text { intention. }\end{array}$ \\
\hline $\mathrm{H}_{1 \mathrm{c}}$ & The perceived usefulness is positive to the attitude. \\
\hline $\mathrm{H}_{1 \mathrm{~d}}$ & The perceived ease of use is positive to the attitude. \\
\hline $\mathrm{H}_{2 \mathrm{a}}$ & Pleasure is positive to the attitude. \\
\hline $\mathrm{H}_{2 \mathrm{~b}}$ & Arousal is positive to the attitude. \\
\hline $\mathrm{H}_{2 \mathrm{c}}$ & Dominance is related to the attitude. \\
\hline $\mathrm{H}_{2 \mathrm{~d}}$ & Dominance is positive to the perceived ease of use. \\
\hline $\mathrm{H}_{3}$ & $\begin{array}{l}\text { The gender variable can regulate the effect of } \\
\text { perceived ease of use on attitude. }\end{array}$ \\
\hline
\end{tabular}

\section{Data Analysis}

The researchers used SPSS 22.0 for single-factor analysis of variance to test the homogeneity of the subjects' information skills in different regions of Taiwan; LISREL 8.80 was used for the analysis of structural equation modeling to construct an integrated model, with the estimation of maximum likelihood as the default estimation method of the software.

\section{RESULT}

Before the results analysis, the researchers first conducted a single-factor analysis of variance in information skills of subjects from different regions (North, Central, South, and East) of Taiwan. The results showed that, in the workshops, the information skills of participants from different regions had no significant difference $(F(3,192)=0.45, p=0.72)$, so it was appropriate to regard these subjects from different regions as a homogeneous group to test the model fit. The following describes the results of the construction of the structural equation modeling in terms of the measured model and the structural model.

\section{A. Measured Model Result}

The analysis of the measured model was to test the validity and reliability of the model. Researchers used discriminant validity and convergent validity as a way to evaluate validity. Fornell and Larker [25] evaluate the discriminant validity by judging whether the AVE (average variance extracted) of each construct is greater than the square of the correlation coefficient of each construct. From the results in Table III, with the measured model meeting this standard, the study shows that the potential constructs of the measured model have discriminant validity; in terms of convergence validity, the AVE value is generally higher than 0.50 and the composite reliability is higher than 0.70 as the assessment of whether convergence validity can be used as an index. As far as the results of Table IV are concerned, the measured model meets these standards. On the whole, the analysis of the discriminant validity and convergence validity shows that the measured model in this study has good validity and reliability, and can be tested for subsequent structural mode.

TABLE III: THE ANALYSIS RESULT OF DISCRIMINANT VALIDITY

\begin{tabular}{|c|c|c|c|c|c|c|c|}
\hline & $\begin{array}{l}\text { Perceived } \\
\text { ease of use }\end{array}$ & $\begin{array}{l}\text { Perceived } \\
\text { usefulness }\end{array}$ & Pleasure & Arousal & Dominance & Attitude & Usage intention \\
\hline Perceived ease of use & 0.84 & & & & & & \\
\hline Perceived usefulness & 0.05 & 0.52 & & & & & \\
\hline Pleasure & 0.37 & 0.12 & 0.90 & & & & \\
\hline Arousal & 0.12 & 0.03 & 0.29 & 0.66 & & & \\
\hline Dominance & 0.50 & 0.10 & 0.73 & 0.24 & 0.87 & & \\
\hline Attitude & 0.45 & 0.44 & 0.38 & 0.31 & 0.29 & 0.80 & \\
\hline Usage intention & 0.27 & 0.36 & 0.23 & 0.19 & 0.18 & 0.63 & 0.77 \\
\hline
\end{tabular}

Note: Diagonal numbers represent the AVE of the construct; numbers outside the diagonal are correlation coefficients between constructs

\section{B. Structural Model Result}

The overall model fit of the structural model can be divided into three parts for evaluation: measures of absolute fit, parsimonious fit measures and incremental fit measures. The summary of the results is shown in Table V. From the table, except that the chi-square value does not meet the recommended standard because it is significant, the other evaluation indicators are ideal. However, because the chi-square value tends to fluctuate with the sample size, the assessment usually refers to other indicators. Overall, in this structural model, the indicators of measures of absolute fit, parsimonious fit measures and incremental fit measures are broadly in line with the recommended standards (except for the chi-square value), which demonstrates the model has a high fitting with empirical data. Therefore, the test results of various coefficients (that is, research hypotheses) in the model can be explored further. 
TABLE IV: THE ANALYSIS RESULT OF CONVERGENT VALIDITY

\begin{tabular}{|c|c|c|c|}
\hline & Factor loadings & Composite reliability & AVE \\
\hline Perceived ease of use & & 0.91 & 0.84 \\
\hline Perceived ease of use parceling 1 & 0.91 & & \\
\hline Perceived ease of use parceling 2 & 0.92 & & \\
\hline Perceived usefulness & & 0.68 & 0.52 \\
\hline Perceived usefulness parceling 1 & 0.79 & & \\
\hline Perceived usefulness parceling 2 & 0.64 & & \\
\hline Pleasure & & 0.95 & 0.90 \\
\hline Pleasure parceling 1 & 0.94 & & \\
\hline Pleasure parceling 2 & 0.96 & & \\
\hline Arousal & & 0.79 & 0.66 \\
\hline Arousal parceling 1 & 0.82 & & \\
\hline Arousal parceling 2 & 0.80 & & \\
\hline Dominance & & 0.93 & 0.87 \\
\hline Dominance parceling 1 & 0.89 & & \\
\hline Dominance parceling 2 & 0.97 & & \\
\hline Attitude & & 0.89 & 0.80 \\
\hline Attitude parceling 1 & 0.89 & & \\
\hline Attitude parceling 2 & 0.90 & & \\
\hline Usage intention & & 0.87 & 0.77 \\
\hline Usage intention parceling 1 & 0.84 & & \\
\hline Usage intention parceling 2 & 0.91 & & \\
\hline
\end{tabular}

TABLE V: EVALUATION INDICATOR OF FIT

\begin{tabular}{|c|c|c|c|c|}
\hline Indicator type & Indicator name & Test value & Test standard & Result \\
\hline \multirow{5}{*}{$\begin{array}{l}\text { Indicator of measures of } \\
\text { absolute fit }\end{array}$} & Chi-square value & 96.86 (significant) & $\begin{array}{l}\text { Not significant is } \\
\text { better }\end{array}$ & Not Ideal \\
\hline & $\begin{array}{l}\text { Chi-square/degrees } \\
\text { of freedom }\end{array}$ & 1.53 & $<3.00$ & Ideal \\
\hline & GFI & 0.95 & $>0.90$ & Ideal \\
\hline & SRMR & 0.06 & $<0.08$ & Ideal \\
\hline & RMSEA & 0.05 & $<0.08$ & Ideal \\
\hline \multirow{2}{*}{$\begin{array}{l}\text { Indicator of } \\
\text { parsimonious fit } \\
\text { measures }\end{array}$} & PGFI & 0.56 & $>0.50$ & Ideal \\
\hline & AIC & 360.54 & $\begin{array}{l}\text { <Independent AIC } \\
(2406.42)\end{array}$ & Ideal \\
\hline \multirow{2}{*}{$\begin{array}{l}\text { Indicator of incremental } \\
\text { fit measures }\end{array}$} & NNFI & 0.97 & $>0.90$ & Ideal \\
\hline & CFI & 0.98 & $>0.90$ & Ideal \\
\hline
\end{tabular}

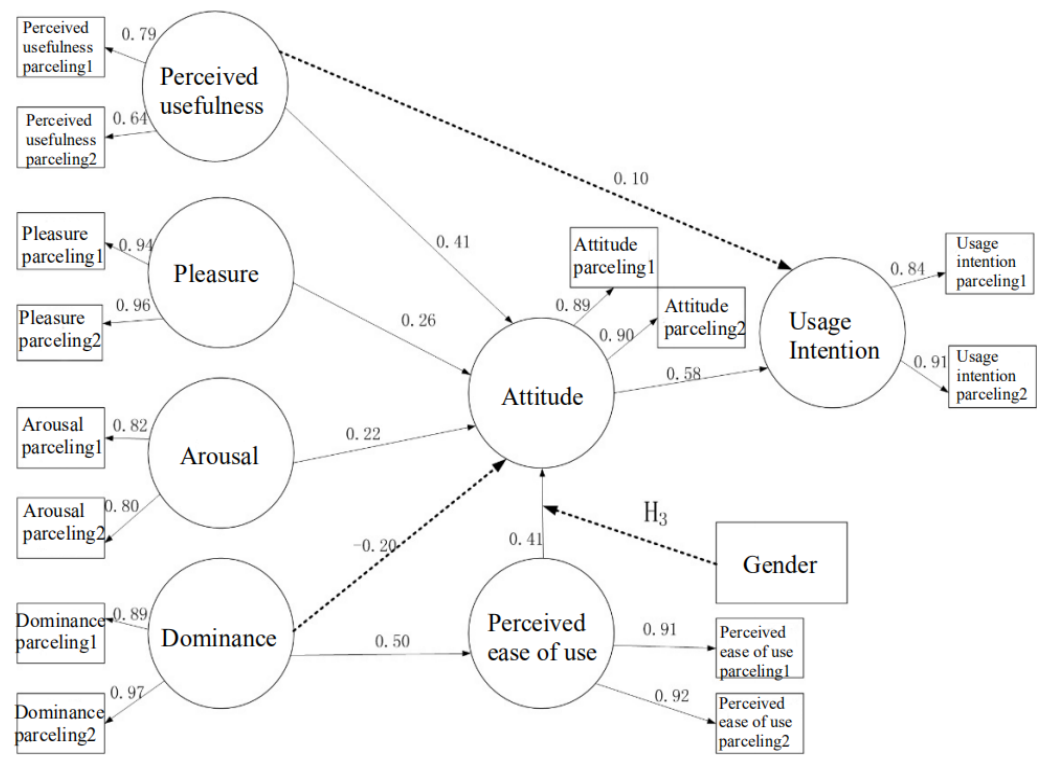

Note: The dotted line indicates that the coefficient has not reached the statistically significant level .

Fig. 3. Research model result

\section{Test Result of Research Hypothesis}

Fig. 3 shows the test results of the model coefficients. Through the graph, we can find that in the research hypothesis related to original TAM, the three assumptions about attitude and usage intention, perceived usefulness and attitude, and perceived ease of use and attitude are all supported, while the assumption that perceived usefulness is related to usage intention is partially supported, that is, perceived usefulness does not directly affect usage intention, and only through an attitude intermediary can it have an indirect positive impact on usage intention $(\mathrm{t}=3.62)$; Among the PAD, the three hypotheses about pleasure and attitude, arousal and attitude, and dominance and perceived ease of use are all supported, but the hypothesis of dominance and 
attitude is only partially supported, that is, the dominance does not directly affect attitude, but only through the intermediary of perceived ease of use can it have an indirect positive effect on attitude( $t=4.27)$. Finally, the researchers set a restricted model: the influence coefficient of female teachers' perceived ease of use to attitude is equal to that of male teachers, then Chi-square difference test was conducted between this restricted model and the unrestricted model. The results showed that the chi-square value was 2.53 , which did not reached a significant level, indicating the influence of perceived ease of use on attitude will not change with different genders. Table VI summarizes the test results of all research hypotheses in this study.

TABLE VI: TEST RESULTS OF RESEARCH HYPOTHESES

\begin{tabular}{|c|c|c|c|c|}
\hline $\begin{array}{l}\text { Research } \\
\text { hypothesis }\end{array}$ & Path & $\begin{array}{l}\text { Regression } \\
\text { coefficient }\end{array}$ & $t$-value & $\begin{array}{l}\text { Test } \\
\text { result }\end{array}$ \\
\hline $\mathrm{H}_{1 \mathrm{a}}$ & The attitude is positive to the usage intention. & 0.58 & 6.51 & Support \\
\hline $\mathrm{H}_{1 \mathrm{~b}}$ & The perceived usefulness is positive to the usage intention. & 0.10 & 1.16 & $\begin{array}{l}\text { Partially } \\
\text { Support }\end{array}$ \\
\hline $\mathrm{H}_{1 \mathrm{c}}$ & The perceived usefulness is positive to the attitude. & 0.41 & 4.13 & Support \\
\hline $\mathrm{H}_{1 \mathrm{~d}}$ & The perceived ease of use is positive to the attitude. & 0.41 & 5.22 & Support \\
\hline $\mathrm{H}_{2 \mathrm{a}}$ & Pleasure is positive to the attitude. & 0.26 & 2.59 & Support \\
\hline $\mathrm{H}_{2 \mathrm{~b}}$ & Arousal is positive to the attitude. & 0.22 & 2.86 & Support \\
\hline $\mathrm{H}_{2 \mathrm{c}}$ & Dominance is related to the attitude. & -0.20 & -1.89 & $\begin{array}{l}\text { Partially } \\
\text { Support }\end{array}$ \\
\hline $\mathrm{H}_{2 \mathrm{~d}}$ & Dominance is positive to the perceived ease of use. & 0.50 & 6.99 & Support \\
\hline $\mathrm{H}_{3}$ & $\begin{array}{l}\text { The gender variable can regulate the effect of perceived } \\
\text { ease of use on attitude. }\end{array}$ & & & $\begin{array}{l}\text { Don't } \\
\text { Support }\end{array}$ \\
\hline
\end{tabular}

\section{DISCUSSION}

The results showed that the integrated model constructed by this research and the empirical data had a good fit, which demonstrates the combination of the original TAM and PAD emotional variables in this research model can effectively explain the technology usage intention of Taiwan college teachers after participating in the online system training. The findings can be used for not only theoretical development but also educational practice.

First of all, as for theoretical development, this study confirmed the necessity of TAM for attitude variables in the context of explaining teachers' intentions to use technology, because the study found that after incorporating attitude variables, the perceived usefulness does not affect the usage intention directly, but the indirect effect produced by the intermediary of the attitude variable is significant. This corresponds to Athiyaman [20]'s view that the more freely the individual is to choose whether to use technology, the more importantly the existence of attitude variables becomes. Furthermore, this study not only verified that the original TAM variable has a significant explanatory effect on the technology usage intention of teachers, but also found that the pleasure, arousal and dominance experienced by these teachers will directly or indirectly influence their attitudes on the technology in the training. In this study, since the influence of attitude on teachers' usage intention has a large effect value, it means that these three emotion types have an important effect on teachers' intention through the attitude intermediary. Although empirical research in the past has found that emotions have an impact on individual's intention to use technology [11]-[13], [22], no research has systematically discussed the effect of different emotion types, and this is the difference between this study and other studies. Furthermore, as far as the results of this research model are concerned, the two emotions of pleasure and arousal are more in line with the general understanding of emotion, that is, emotions are an intuitive response that is less cognitively thought, so the effect of pleasure and arousal on the individual's attitude is direct. However, dominance is not so. It's impact on individual attitudes will only be generated after another cognitive assessment (that is, perceived ease of use). As for what causes these three emotions to have different effects on the technology usage? This part is limited by the method of questionnaire survey and cannot be answered in this study. In the future, qualitative analysis of in-depth interviews can be used to find out the reasons.

Secondly, as for educational practice, this study found that perceived usefulness, perceived ease of use, and emotions such as pleasure, arousal, and dominance all directly or indirectly affect teachers' intention to use technology after attending training activities. The results have a certain degree of guidance for the future training plan. For example, from the perspective of perceived ease of use, when training instructors explain the project based learning online system, they should try to disassemble the operation into small blocks, and make sure that the teacher is proficient in the previous area and then go to the next block; from the perspective of perceived usefulness, the instructor should let the teachers understand the benefits of this system for PBL; in terms of emotional impact, the instructor should have a certain degree of mastery of the teachers' emotion, and special attention should be paid to how to stimulate teachers' pleasure and arousal in training activities.

Finally, in addition to its contributions in theoretical development and educational practice, this study found that the impact of perceived ease of use on attitudes does not differ from gender to gender. In fact, in some early empirical research results, there are still conclusions that both sexes have different experience in using technology [11], [25], so the researchers assumed that the influence of perceived ease of use on attitude will be changed with gender variables. However, this hypothesis was not supported in this study. This may reflect that with the development of the times, the experience difference in technology use between the genders has gradually disappeared, but the speculation still needs 
more research to test.

\section{CONCLUSION}

PBL emphasizes that students explore and integrate relevant information independently to conceive solutions of problems arranged by teachers. This kind of teaching method based on students' self-planning learning is very suitable for the requirements in distance education. Therefore, in the development of distance education, PBL is indispensable, and in order to help teachers efficiently implement PBL courses, the sustainable development of the system is particularly critical. Aiming on teachers who attended the project based learning online system training activities, this research explored the impact of various latent variables on the technology usage intention. Researchers integrated TAM into PAD and constructed new models in the form of structural equation modeling, with 196 college teachers from Taiwan as subjects conducting the study. The analysis results of the structural equation modeling showed that the integrated model fits well with the empirical data. The research hypotheses found that: Among TAM, the variables of perceived usefulness and perceived ease of use were positive to the attitude and the attitude was positive to the intention of technology usage; Among PAD, the variables of pleasure and arousal were positive to the attitude and the variable of dominance was positive to the variable of perceived ease of use. This study not only confirmed the explanatory power of the original TAM variables in teacher training activities, but also found that different types of emotions have different impacts on the individual technology usage. The findings not only develop the current theory, but also contribute to the teaching plan of training activities in the future.

\section{RESEARCH LIMITATION AND SUGGESTION FOR FUTURE RESEARCH}

In this study, the multi-group analysis of structural equation modeling was used to test the adjustment effect of gender variables on the influence of perceived ease of use on attitudes. This method is generally a common practice in dealing with adjustment variables as nominal attributes. However, in this study the ratio of men and women was not balanced, so the gender adjustment effect test had the problem of unequal number of the two groups. Although the researchers included all the teachers participating in this training activity as the test samples, they still cannot overcome this problem. Due to this limitation, the result of this study that gender lacks of adjustment effect on the impact of perceived ease of use on attitude should be temporarily inconclusive, especially the result is different from past empirical studies. In consideration of the discussion that whether different genders have difference in technology usage has always been an important research topic, and it is worth further exploration, therefore, it is recommended that in the future, the problem of unequal number of subjects between the sexes can be improved to re-examine whether male and female teachers are significantly different with the regression coefficients of this model. In addition, the result that the three emotions have different impacts on the individual technology usage is limited by the method of questionnaire survey used in this study, so it is impossible to figure out the reasons behind it. It is recommended that future research can be conducted in depth interview to find a reasonable explanation.

\section{CONFLICT OF INTEREST}

The authors declare no conflict of interest.

\section{AUTHOR CONTRIBUTIONS}

Yiming Qu wrote, reviewed and edited the paper; I-Hua Chen conducted the research, analyzed the data, implemented project management and funding acquisition. All authors had approved final version.

\section{REFERENCES}

[1] E. Cho, "International cooperative project-based learning using internet web board for designing anchored instruction in Korean elementary classroom," Journal of Educational Technology, vol. 16, pp. 247-266, April 2000

[2] D. R. Garrison, "Online community of inquiry review: Social, cognitive, and teaching presence issues," Journal of Asynchronous Learning Networks, vol. 11, no.1, pp. 61-72, April 2007.

[3] P. Kim, J.-S. Hong, C. Bonk, and G. Lim, "Effects of group reflection variations in project-based learning integrated in a Web 2.0 learning space," Interactive Learning Environments, vol. 19, no. 4, pp. 333-349, September 2009

[4] J. H. L. Koh, S. C. Herring, and K. F. Hew, "Project-based learning and student knowledge construction during asynchronous online discussion," The Internet and Higher Education, vol. 13, no. 4, pp. 284-291, December 2010.

[5] F. D. Davis, "Perceived usefulness perceived ease of use and user acceptance of information technology," Mis Quarterly, vol. 13, pp. 319-340, September 1989.

[6] X. H. Ren and N. Zhai, "An empirical research of Information technology acceptance behaviors of teachers in college classroom teaching," Distance Education Journal, vol. 30, pp. 84-90, February 2012.

[7] F. Gao, "The study of factors of teacher's adoption of network teaching in higher vocational technical college - Taking a vocational technical college as an example," Distance Education in China, pp. 32-38, September 2011.

[8] S. Zhang et al., "Construction of teacher's network teaching behavior model based on TPB and TAM," Distance Education in China, pp. 64-69, February 2014.

[9] S. Zhang and Y. F. Li, "Study on university teachers' network teaching behavior based on technology acceptance model," Journal of Distance Education, pp. 56-63, June 2014.

[10] L. N. Yang and Z. J. Yan, "An empirical study of online learner performance from an information technology acceptance perspective," Distance Education in China, 4, pp. 36-40, April 2011.

[11] N. Anderson, C. Lankshear, C. Timms, and L. Courtney, "Because it's boring, irrelevant and I don't like computers': Why high school girls avoid professionally-oriented ICT subjects," Computers \& Education, vol. 50, pp. 1304-1318, May 2008.

[12] R. H. Kay, "The impact of preservice teachers' emotions on computer use: a formative analysis," Journal of Educational Computing Research, vol. 36, pp. 455-479, June 2007.

[13] M. J. Sanchez-Franco, "WebCT - The quasimoderating effect of perceived affective quality on an extending Technology Acceptance Model," Computers \& Education, vol. 54, pp. 37-46, January 2010.

[14] M. Gong, Y. Xu, and Y. Yu, "An enhanced technology acceptance model for web-based learning," Journal of Information Systems Education, vol. 15, pp. 365-374, January 2004.

[15] P. J.-H. Hu, T. H. K. Clark, and W. W. Ma, "Examining technology acceptance by school teachers: a longitudinal study," Information \& Management, vol. 41, pp. 227-241, December 2003.

[16] A. Mehrabian, "Pleasure-arousal-dominance: A general framework for describing and measuring individual differences in temperament," Current Psychology, vol. 14, pp. 261-292, December 1996. 
[17] P. Walla, G. Brenner, and M. Koller, "Objective measures of emotion related to brand attitude: a new way to quantify emotion-related aspects relevant to marketing," PLOS ONE, vol. 6, p. e26782, November 2011

[18] V. Venkatesh and M. G. Morris, "Why don't men ever stop to ask for directions? gender, social influence, and their role in technology acceptance and usage behavior," MIS Quarterly, vol. 24, pp. 115-139, March 2000.

[19] A. Athiyaman, "Cognitive, affective and behavioural responses to internet-connected computer requirement: A study among enrolling distance education students in a print-based environment," Academy of Educational Leadership Journal, vol. 6, pp. 33-48,

[20] S. Y. Park, "An analysis of the technology acceptance model in understanding university students' behavioral intention to use e-learning," Educational Technology \& Society, vol. 12, pp. 150-162, 2009.

[21] J. C. Hong et al., "Applying the technology acceptance model in a study of the factors affecting usage of the Taiwan digital archives system," Computers \& Education, vol. 57, pp. 2086-2094, November 2011.

[22] G. C. Bruner and A. Kumar, "Explaining consumer acceptance of handheld Internet devices," Journal of Business Research, vol. 58, pp. 553-558, May 2005.

[23] K. O'Regan, "Emotion and e-learning," Journal of Asynchronous Learning Networks, vol. 7, pp. 78-92, September 2003.

[24] C. Chou and M. J. Tsai, "Gender differences in Taiwan high school students' computer game playing," Computers in Human Behavior, vol. 23, pp. 812-824, January 2007.
[25] C. Fornell and D. F. Larcker, "Evaluating structural equation models with unobservable variables and measurement error," Journal of Marketing Research, vol. 18, pp. 39-50, March 1981.

Copyright $\odot 2021$ by the authors. This is an open access article distributed under the Creative Commons Attribution License which permits unrestricted use, distribution, and reproduction in any medium, provided the original work is properly cited (CC BY 4.0).

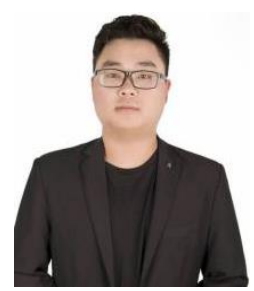

Yiming Qu was born in Zhengzhou, Henan, China, in 1992. He is a 1st year PhD student majoring in educational management at Krirk University, Thailand. He also is a teacher at the Entrepreneurship Academy of Zhengzhou Shengda University Of Economics and Trade Management College. And Dr. Qu's research interest is blended teaching.

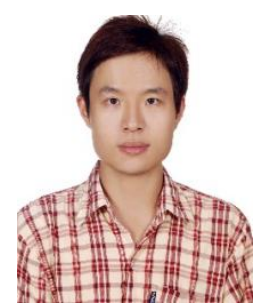

I-Hua Chen was born in Taipei city, Taiwan in 1981 $\mathrm{He}$ is a professor in the Chinese Academy of Education Big Data, Qufu Normal University in Qufu City of Shandong province, China. He received the doctor's degree in Cheng-Kung University in 2014, majoring in digital learning and psychometrics. His current interests are secondary data analysis in educational issues and application of psycho-metrics in educational technology issues. 